\title{
Coastal sea level response to the tropical cyclonic forcing in the northern Indian Ocean
}

\author{
P. Mehra ${ }^{1}$, M. Soumya ${ }^{1}$, P. Vethamony ${ }^{1}$, K. Vijaykumar ${ }^{1}$, T. M. Balakrishnan Nair ${ }^{2}$, Y. Agarvadekar ${ }^{1}$, K. Jyoti ${ }^{1}$, \\ K. Sudheesh ${ }^{1}$, R. Luis ${ }^{1}$, S. Lobo ${ }^{1}$, and B. Harmalkar ${ }^{1}$ \\ ${ }^{1}$ CSIR-National Institute of Oceanography (NIO), Goa, India \\ ${ }^{2}$ Indian National Centre for Ocean Information Services (INCOIS), Hyderabad, India
}

Correspondence to: P. Mehra (pmehra@nio.org)

Received: 13 December 2013 - Published in Ocean Sci. Discuss.: 20 February 2014

Revised: 22 December 2014 - Accepted: 23 December 2014 - Published: 3 February 2015

\begin{abstract}
The study examines the observed storm-generated sea level variation due to deep depression (event 1: E1) in the Arabian Sea from 26 November to 1 December 2011 and a cyclonic storm "THANE" (event 2: E2) over the Bay of Bengal during 25-31 December 2011. The sea level and surface meteorological measurements collected during these extreme events exhibit strong synoptic disturbances leading to storm surges of up to $43 \mathrm{~cm}$ on the west coast and $29 \mathrm{~cm}$ on the east coast of India due to E1 and E2. E1 generated sea level oscillations at the measuring stations on the west coast (Ratnagiri, Verem and Karwar) and east coast (Mandapam and Tuticorin) of India with significant energy bands centred at periods of 92, 43 and $23 \mathrm{~min}$. The storm surge is a well-defined peak with a half-amplitude width of 20,28 and $26 \mathrm{~h}$ at Ratnagiri, Verem and Karwar, respectively. However, on the east coast, the sea level oscillations during Thane were similar to those during calm period except for more energy in bands centred at periods of $\sim 100,42$ and 24 min at Gopalpur, Gangavaram and Kakinada, respectively. The residual sea levels from tide gauge stations in Arabian Sea have been identified as Kelvin-type surges propagating northwards at a speed of $\sim 6.5 \mathrm{~m} \mathrm{~s}^{-1}$ with a surge peak of almost constant amplitude. Multi-linear regression analysis shows that the local surface meteorological data (daily mean wind and atmospheric pressure) is able to account for $\sim 57$ and $\sim 69 \%$ of daily mean sea level variability along the east and west coasts of India. The remaining part of the variability observed in the sea level may be attributed to local coastal currents and remote forcing.
\end{abstract}

\section{Introduction}

Tropical cyclones (TCs) are the most destructive weather systems on the earth, producing intense winds, resulting in high surges, meteotsunamis, torrential rains, severe floods and usually causing damage to property and loss of life. In the northern Indian Ocean, both the Bay of Bengal (BOB) and the Arabian Sea (AS) are potential genesis regions for cyclonic storms. Intense winds associated with TCs, blowing over a large water surface, cause the sea surface to pile up on the coast and leads to sudden inundation and flooding of the vast coastal regions. Also, the heavy rainfall causes flooding of river deltas in combination with tides and surges. A number of general reviews and description of individual cyclones and associated surges in the BOB and the AS have been published previously by several investigators (Murty et al., 1986; Dube et al., 1997; Sundar et al., 1999; Fritz et al., 2010; Joseph et al., 2011). Developments in storm surge prediction in the Bay of Bengal and the Arabian Sea have been highlighted by Dube et al. (2009) and references therein (e.g. Das, 1994; Chittibabu et al., 2000, 2002; Dube et al., 2006; Jain et al., 2007; Rao et al., 2008).

Apart from the studies carried out with a view to assessing the coastal vulnerability, few studies concentrated on the variations in characteristics of different oceanographic parameters in response to tropical cyclones. Joseph et al. (2011) examined the response of the coastal regions of eastern Arabian Sea (AS) and Kavaratti Island lagoon to the tropical cyclonic storm "Phyan", during 9-12 November 2009 until its landfall at the northwest coast of India, based on in situ and satellite-derived measurements. Mehra et al. (2012) reported similarities in the spectral characteristics of sea level oscilla- 
tions in the Mandovi estuary of Goa in the eastern Arabian Sea due to cyclones (June 2007 and November 2009) and the Sumatra geophysical tsunami (September 2007). Wang et al. (2012) reported the variations in the oceanographic parameters due to the tropical Cyclone Gonu, which passed over a deep autonomous mooring system in the northern Arabian Sea and a shallow cabled mooring system in the Sea of Oman. Near-inertial oscillations at all moorings from thermocline to seafloor were observed to be coincident with the arrival of Gonu. Sub-inertial oscillations with periods of $2-$ 10 days were recorded at the post-storm relaxation stage of Gonu, primarily in the thermocline of the deep array and at the onshore regions of the shallow array. Antony and Unnikrishnan (2013) used hourly tide gauge data at Chennai, Visakhapatnam and Paradip along the east coast of India and at Hiron Point, at the head of Bay of Bengal, to analyse statistically the tide-surge interaction. Recently, Rao et al. (2013) simulated surges and water levels along the east coast of India using an advanced 2-D depth-integrated circulation model (ADCIRC-2DDI).

It is necessary that the problem of storm surge must be seriously addressed by the countries of the various regions through collective efforts and in an integrated manner. In the present study, the objective is to examine the characteristic of the sea level oscillations at different topographic locations in the AS and the BOB due to the meteorological events. Our interest is confined to a few minutes to days and analysis of the spectral features of sea level oscillations in the two basins.

\section{Data and methodology}

In the present study, we report the response of the sea level to the episodic meteorological events at various coastal and Island locations of India from 1 September 2011 to 31 January 2012. Study encompasses two episodic meteorological events: (i) deep depression in November 2011 (E1) in the AS and (ii) the tropical Cyclone Thane (E2) in the BOB as shown in Fig. 1. Summary of observations is given in Table 1. The radar gauge (RG), which measures sea level, is described in detail by Prabhudesai et al. $(2006,2008)$ and the evaluation and comparative studies have been reported by Mehra et al. (2013). RG acquires samples over $30 \mathrm{~s}$ window at $1 \mathrm{~min}$ interval and the average over $5 \mathrm{~min}$ is recorded at $5 \mathrm{~min}$ interval. The surface meteorological variables are collected by autonomous weather station (NIO-AWS). AWS samples (wind, air temperature, air pressure and relative humidity) data every $10 \mathrm{~s}$ over a window of $10 \mathrm{~min}$, averaged and then recorded at every $10 \mathrm{~min}$ interval. In the present study, we have used time-series data at 5 (10) min interval from the RG (AWS). Both the systems have been designed and developed in the Marine Instrumentation Division, CSIR-NIO, Goa. Summary of observations from different coastal and Is-

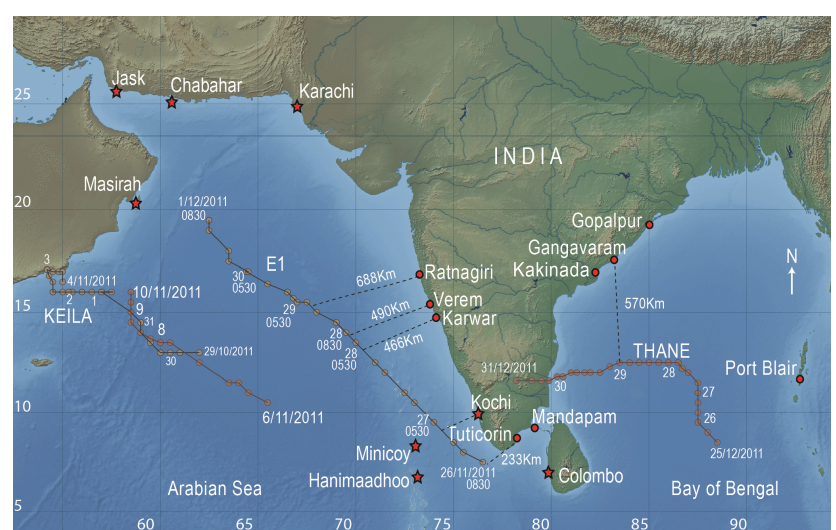

Figure 1. Study location showing the tracks of meteorological events during the year 2011. Note: sea level data at Colombo, Kochi, Karachi, Chabahar, Jask, Masirah, Minocoy and Hanimaadhoo are downloaded from www.gloss-sealevel.org and are shown with red stars. (Time is in Indian standard time (IST).)

land locations of India are provided in Table 1 and the periods covered for different events are as follows:

- Event 1 (E1): 26 November to 1 December 2011, occurrence of deep depression in the Arabian Sea.

- Event 2 (E2): 25-31 December 2011, passage of Thane cyclone in the Bay of Bengal.

The tropical cyclone track data from India Meteorological Department (IMD, www.imd.gov.in), Joint Typhoon Warning Center (JTWC, www.usno.navy.mil/JTWC/) and UNISYS-Unisys Weather (http://weather.unisys.com/ hurricane/) are shown Fig. 2. The storm translational speed is calculated using the distance travelled between two consecutive positions and time interval. The average differences in wind speeds as shown in Fig. 2a and d between IMD and JTWC, and IMD and Unisys are $-1.1(-4.2)$ and -3.7 $(-2.8) \mathrm{m} \mathrm{s}^{-1}$ during E1 (E2). The sea level pressure reported by IMD and JTWC is similar during E1 (Fig. 2b); however during E2, the minimum sea level pressure differed by $\sim-11 \mathrm{mb}$ with a time lag of $\sim 3 \mathrm{~h}$ (Fig. 2e). The cyclone translation speed estimated using JTWC and Unisys data during E1 varied between 2.5 and $6.4 \mathrm{~m} \mathrm{~s}^{-1}$, except for two spikes of $\sim 9 \mathrm{~m} \mathrm{~s}^{-1}$ observed in Unisys data (Fig. 2c). Similarly, the cyclone translation speed estimated using JTWC and Unisys data during E2 varied between 1.0 and $4.5 \mathrm{~m} \mathrm{~s}^{-1}$, except for a few spikes of $\sim 5-7 \mathrm{~m} \mathrm{~s}^{-1}$ (Fig. 2f). Cyclone translation speed using IMD data is fluctuating as the data are available at every $3 \mathrm{~h}$ interval, whereas data from the other two sites is at every $6 \mathrm{~h}$. However, the mean cyclone speed during E1 (E2) from IMD data is $7.8(2) \mathrm{m} \mathrm{s}^{-1}$.

Sea level data are de-tided using TASK tidal analysis and prediction program (Bell et al., 2000) to obtain sea level residual (SLR). A multi-linear regression model linking sea level and atmospheric parameters has been established. The 
Table 1. Summary of observations from different coastal and Island locations of India from 1 September 2011 to 31 January 2012 . The CSIR-NIO radar gauge (RG) measures sea level (cm) and the CSIR-NIO autonomous weather station (AWS) provides surface meteorological variables such as winds, atmospheric pressure and air temperature.

\begin{tabular}{|c|c|c|c|c|c|c|}
\hline \multirow[b]{2}{*}{ Sr No } & \multirow[b]{2}{*}{ Measurement Station } & \multicolumn{2}{|c|}{$\begin{array}{l}\text { Latitude and } \\
\text { Longitude }\end{array}$} & \multirow[b]{2}{*}{ Location type } & \multirow[b]{2}{*}{ System } & \multirow{2}{*}{$\begin{array}{l}\text { Distance between } \\
\text { AWS \& RG (m) }\end{array}$} \\
\hline & & Lat $\left({ }^{\circ} \mathrm{N}\right)$ & Lon $\left({ }^{\circ} \mathrm{E}\right)$ & & & \\
\hline \multirow[t]{2}{*}{1} & Gopalpur, Odisha & 19.3081 & 84.9613 & Harbour & AWS & 255 \\
\hline & & 19.3069 & 84.9634 & & Radar gauge & \\
\hline \multirow[t]{2}{*}{2} & Gangavaram, Andhra Pradesh & 17.6174 & 83.2322 & Harbour & AWS & 726 \\
\hline & & 17.6235 & 83.2295 & & Radar gauge & \\
\hline \multirow[t]{2}{*}{3} & Kakinada, Andhra Pradesh & 16.9764 & 82.2832 & Harbour & AWS & 2 \\
\hline & & 16.9764 & 82.2832 & & Radar gauge & \\
\hline \multirow[t]{2}{*}{4} & Mandapam, Tamil Nadu & 9.2763 & 79.1295 & Boundary of Palk Strait & AWS & 615 \\
\hline & & 9.2713 & 79.1321 & $\&$ Gulf of Mannar & Radar gauge & \\
\hline 5 & Tuticorin, Tamil Nadu & 8.7500 & 78.2021 & Gulf of Mannar & Radar gauge & - \\
\hline \multirow[t]{2}{*}{6} & Port Blair, Andaman \& Nicobar Islands & 11.7099 & 92.7386 & Open ocean & AWS & 2984 \\
\hline & & 11.6884 & 92.7222 & & Radar gauge & \\
\hline \multirow[t]{2}{*}{7} & Karwar, Karnataka & 14.8464 & 74.1317 & Open ocean & AWS & 5154 \\
\hline & & 14.8030 & 74.1144 & & Radar gauge & \\
\hline \multirow[t]{2}{*}{8} & Verem, Goa & 15.4554 & 73.8022 & Mandovi estuary & AWS & 5265 \\
\hline & & 15.5019 & 73.8120 & & Radar gauge & \\
\hline \multirow[t]{2}{*}{9} & Ratnagiri, Maharashtra & 16.8926 & 73.2758 & Cove & AWS & 525 \\
\hline & & 16.8890 & 73.2853 & & Radar gauge & \\
\hline
\end{tabular}

model can be described in general as follows:

$\eta=B_{0}+B_{1} \tau_{U}+B_{2} \tau_{V}+B_{3} A_{P}+\epsilon$,

In the above expression, sea level residual $(\eta)$ is the dependent variable and the independent variables are cross-shore (along-shore) wind stress $\tau_{U}\left(\tau_{V}\right)$ and atmospheric pressure $\left(A_{P}\right)$. Likewise $B_{0}, B_{1}, B_{2}$ and $B_{3}$ are the coefficients of regression and $\epsilon$ is the difference between the measured SLR and estimated SLR using multi-linear regression. The crossshore (along-shore) wind stress $\tau_{U}\left(\tau_{V}\right)$ is estimated using cross-shore $(U)$ and along-shore $(V)$ component of winds as follows:

$\tau_{U}=\rho_{A} C_{D} U \sqrt{U^{2}+V^{2}}$

$\tau_{V}=\rho_{A} C_{D} V \sqrt{U^{2}+V^{2}}$

$\rho_{A}=1.3 \mathrm{~kg} \mathrm{~m}^{-3}$ is the density of air and $C_{D}=1.2 \times 10^{-3}$ is the drag coefficient. The regression is performed using daily mean SLR, $\tau_{U}, \tau_{V}$ and $A_{P}$. For each month, coefficients of regression of the daily data are obtained to estimate the SLR, which is then merged to generate the time series of estimated SLR for the duration of September 2011 to January 2012.

\section{Observed coastal sea level response to meteorological events}

The tracks of the meteorological event under study, which occurred in the AS (the BOB) are shown in Fig. 1. The data and information about these episodic meteorological events is taken from www.imd.gov.in.

The meteorological event (E1) in AS, developed on 26 November 2011 at $7.5^{\circ} \mathrm{N}, 76.5^{\circ} \mathrm{E}$ near the southern tip of the Indian sub-continent and moved north-westwards. By 28 November 2011 00:00 UTC, it intensified as a deep depression with maximum sustained surface winds reaching up to $15 \mathrm{~m} \mathrm{~s}^{-1}$ (Fig. 2a) and the minimum estimated central pressure (ECP) $\sim 998 \mathrm{mb}$ (Fig. 2b). The average translational speed of this system remained steady to $\sim 6.5 \mathrm{~m} \mathrm{~s}^{-1}$. However, during the minimum ECP, the translation speed also decreased to $\sim 2 \mathrm{~m} \mathrm{~s}^{-1}$ on 29 November and increased to $\sim 6 \mathrm{~m} \mathrm{~s}^{-1}$ on 30 November (Fig. 2c). The system weakened into a well-marked low pressure area over the west central Arabian Sea.

The cyclonic system named "Thane" initially originated as a depression on 25 December 2011 at $8.5^{\circ} \mathrm{N}, 88.5^{\circ} \mathrm{E}$ and moved north-westwards (Fig. 1). Thane intensified into a very severe cyclonic storm with maximum sustained surface winds peaked up to $\sim 45 \mathrm{~m} \mathrm{~s}^{-1}$ as shown in Fig. $2 \mathrm{~d}$ and ECP falling to $\sim 956 \mathrm{mb}$ (Fig. 2e). The cyclone track turned westwards on 28 December, with an average translational speed of $\sim 4 \mathrm{~m} \mathrm{~s}^{-1}$ and then became steady at $\sim 3.5 \mathrm{~m} \mathrm{~s}^{-1}$ as shown in Fig. 2f. The translation speed of a storm can exert significant control on the intensity of storms by modulating the strength of the negative effect of the storm-induced sea surface temperature (SST) reduction on the storm intensification (Mei et al., 2012). Thane crossed the Tamil Nadu coast just 

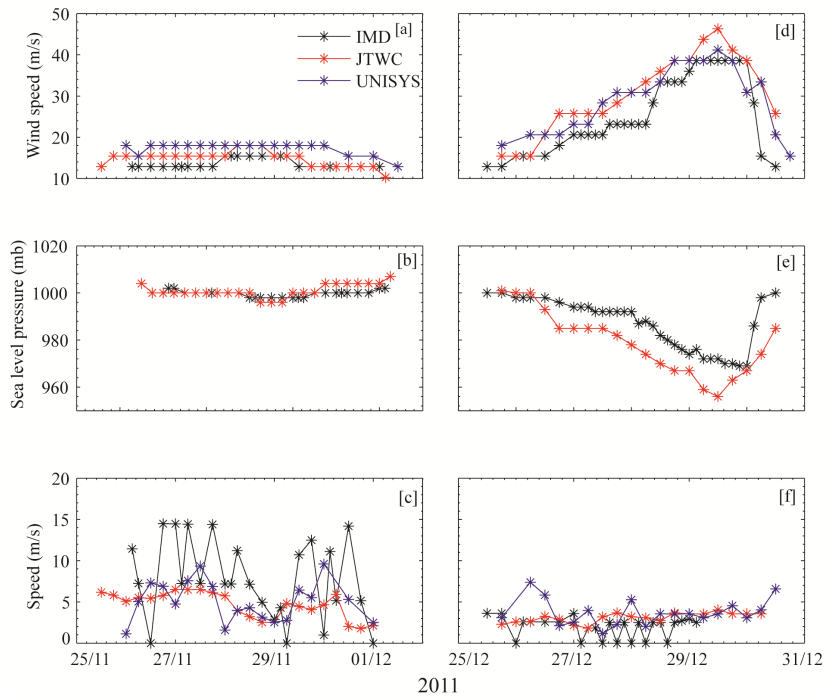

Figure 2. Cyclone parameters during E1 (a) wind speed, (b) sea level pressure, and (c) storm forward translation speed. Similarly, cyclone parameters during E2 (d) wind speed, (e) sea level pressure, and (f) storm forward translation speed. Note: IMD-India Meteorological Department; JTWC-Joint Typhoon Warning Center; UNISYS-Unisys Weather (http://weather.unisys.com/hurricane/).

south of Cuddalore between 01:00 and 02:00 UTC of 30 December 2011 and weakened into a well-marked low pressure area over northern Kerala and its neighbourhood.

\subsection{Response of sea level to depression in the Arabian Sea (2011)}

The sea level residuals (SLR) at Ratnagiri, Verem and Karwar are shown in Fig. 3. The visual observation of SLR indicates that it is normally within $\pm 25 \mathrm{~cm}$ at all the three locations. Keila and the subsequent depression from 29 October to 10 November are not able to generate noticeable sea level variations, probably due to large distance of the measurement sites from the cyclonic tracks. For example, the distance of Verem to the trajectory of Keila's ECP is $\sim 1554 \mathrm{~km}$. The variance of SLR observed during 29 October to 10 November at Ratnagiri, Verem and Karwar is $\sim 26.1,21.6$ and $25.8 \mathrm{~cm}^{2}$, respectively (Fig. 3). However, the deep depression which originated on 26 November 2011 (E1) was in the near proximity to the measurement sites. For example, the distance of Verem from the depression centre on 28 November 2011 was $\sim 490 \mathrm{~km}$ (Fig. 1). E1 was able to inflict surges at Ratnagiri, Verem and Karwar which peaked up to $\sim 43 \mathrm{~cm}$ with SLR variance of $\sim 119.4,95.4$ and $108.2 \mathrm{~cm}^{2}$, respectively, during E1 (Fig. 3a-c). The storm surge is a well-defined peak with a half- width (see Fandry et al., 1984) of $\sim 25 \mathrm{~h}$ (Table 2). The local surface meteorological conditions along with SLR are shown in Fig. 4. During E1 (26 November to 1 December 2011), the wind variance was $\sim 1.7,4.8$ and $0.8 \mathrm{~m}^{2} \mathrm{~s}^{-2}$ with wind speeds peaking up to $\sim 8.5 \mathrm{~m} \mathrm{~s}^{-1}$ at Ratnagiri

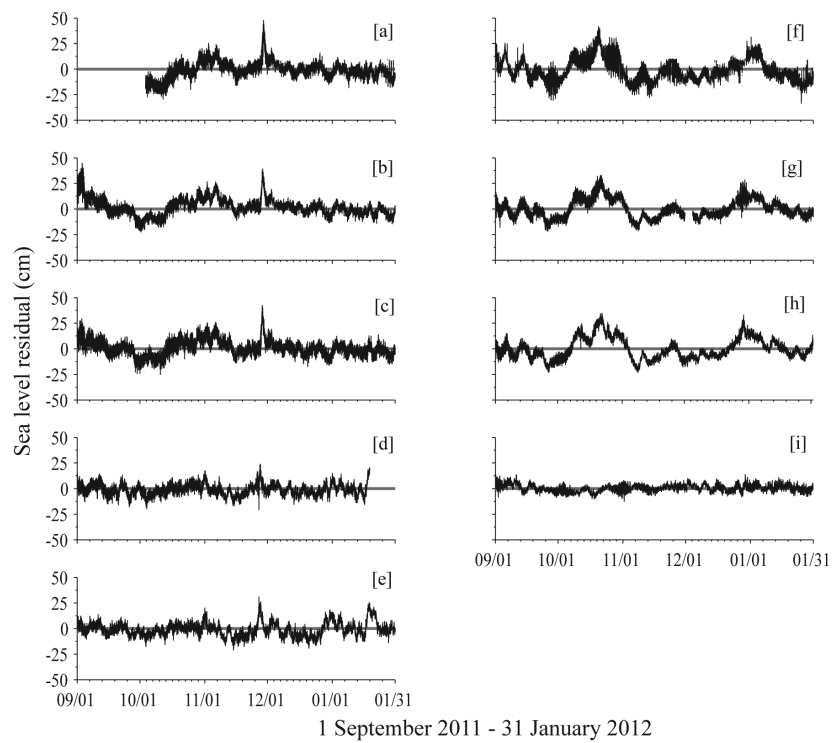

Figure 3. Sea level residual (SLR) at (a) Ratnagiri, (b) Verem, (c) Karwar, (d) Tuticorin, (e) Mandapam, (f) Gopalpur, (g) Gangavaram, (h) Kakinada and (i) Port Blair.

and Verem (Fig. 4a.2-b.2). At Karwar, the wind energy is less compared to the other two sites, still the SLR peaks are of same magnitude (Fig. 4c.1-c.2), indicating the effect of long waves generated by the forcing due to $\mathrm{E} 1$ in the open ocean. The wind direction (Fig. 4a.3-c.3) stabilised with respect to the north (Table 2) at Ratnagiri, Verem and Karwar, respectively. The atmospheric pressure anomaly (Fig. 4a.4c.4) shows a variance of $\sim 3.6 \mathrm{mb}^{2}$ and falls by $\sim 6.0 \mathrm{mb}$ during E1 at the three stations. However, anomalous temperature variations due to E1 were not observed (Fig. 4a.5-c.5), but the range narrowed, which is also the case with relative humidity at the three stations (Fig. 4a.6-c.6).

\subsection{Response of sea level to meteorological events on the east coast of India}

Response of sea level as storm surges at different sites, to the tropical cyclone Thane, E2, which occurred in the BOB are shown (listed) in Fig. 3 (Table 3). SLR exhibits maximum oscillations (variance) of $\sim 27 \mathrm{~cm}\left(47.8\right.$ and $11.7 \mathrm{~cm}^{2}$ ) at Gopalpur (Fig. 5a.1) and Gangavaram (Fig. 5b.1), respectively. At Kakinada, the SLR peaked up to $33 \mathrm{~cm}$, with a variance of $23.3 \mathrm{~cm}^{2}$ during E2. Minor dip in SLR $\sim 14.1$, 10.3 and $15.0 \mathrm{~cm}$ was also observed at the coastal sites located in the AS (Ratnagiri, Verem and Karwar) due to E2 (Fig. 3a-c). However, at the Island station, Port Blair, the SLR variations are within $\pm 10 \mathrm{~cm}$, and less than at sites north of Thane (Fig. 3i). The SLR variability at Mandapam and Tuticorin was less compared to other sites north of Thane track (Fig. 3d and e), probably due to the following two reasons: (i) the geometrical amplification of the open-ocean waves as they propagate northwards and (ii) wind speeds 
Table 2. Meteorological and sea level observations at Ratnagiri, Verem and Karwar during E1 from 26 November to 1 December 2011. Time is in Indian standard time (IST).

\begin{tabular}{cllll}
\hline Sr No & Variables & Ratnagiri & Verem & Karwar \\
\hline 1 & Sea level residual (SLR in cm) & 47 & 39 & 42 \\
2 & SLR rise time from zero-maxima (h) & 44.16 & 39.33 & 32.58 \\
3 & SLR fall time from maxima-zero (h) & 48.5 & 45.25 & 42.25 \\
4 & SLR peak time & 29 Nov 2011 03:15 & 28 Nov 2011 18:00 & 28 Nov 2011 12:25 \\
5 & Maximum wind speed $\left(\mathrm{m} \mathrm{s}^{-1}\right.$ ) & 7.4 & 9.6 & 4.3 \\
6 & Half amplitude surge width duration $(\mathrm{h})$ & 20 & 28 & 26 \\
7 & Wind direction (degrees) & 253 & 112 & 246 \\
8 & Air temperature, reduction in range $\left({ }^{\circ} \mathrm{C}\right)$ & $8.3-3.0$ & $13.3-6.8$ & $15.5-8.3$ \\
9 & Atmospheric pressure fall $(\mathrm{mb})$ & 5.8 & 6.3 & 5.9 \\
10 & Relative humidity range fall $(\%)$ & $62.0-40.4$ & $65.4-41.3$ & $64.8-33.8$ \\
\hline
\end{tabular}

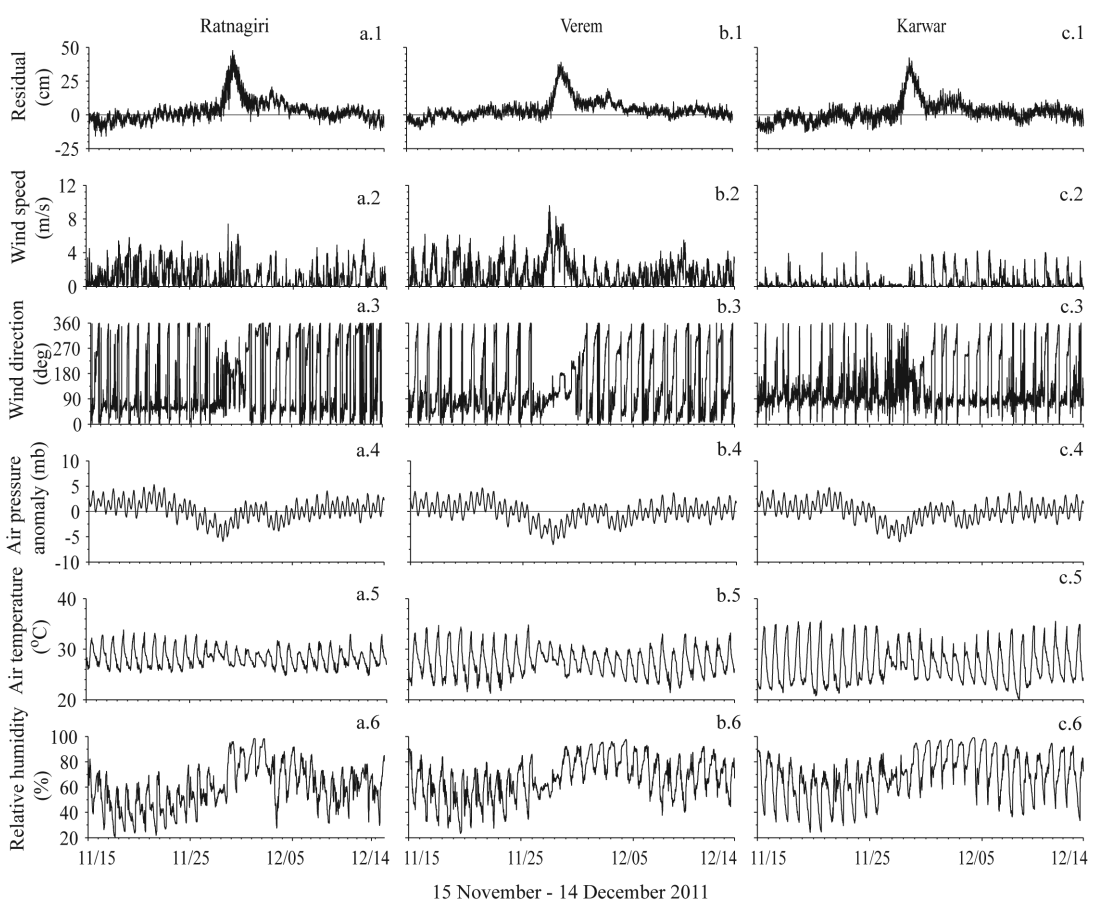

Figure 4. Sea level residual and surface meteorological parameters during the episodic event E1. (a.1 to a.6) SLR, wind speed, wind direction, atmospheric pressure anomaly, air temperature and relative humidity at Ratnagiri, Maharashtra. (b.1 to b.6) same as in (a) at Verem, Goa. (c.1 to c.6) same as in (a) at Karwar, Karnataka. The atmospheric pressure anomaly is estimated by subtracting the mean atmospheric pressure (1 September 2011 to 31 January 2012) from the measured atmospheric pressure for respective stations.

are less near the central depression point and increases towards the periphery. SLR rise is also seen at Mandapam (Tuticorin) by $\sim 24.3(23.1) \mathrm{cm}$ even during E1. The local surface meteorological conditions along with SLR are shown in Fig. 5. The large scale extent of E2 is evident in wind and atmospheric pressure measurements at all the three locations and very similar meteorological conditions exist at Gangavaram and Kakinada. At Gopalpur, the winds were weak as compared to the other two southern locations with maximum wind speed reaching up to $\sim 6 \mathrm{~m} \mathrm{~s}^{-1}$; the direction also fluctuated during E2 and remained southerly after 5 Jan- uary 2012 and maintained this direction till 10 January 2012 (Fig. 5a.2 and a.3, Table 3). During E2, the wind speed remained high from 26 December 2011 till 4 January 2012. The wind speed peaked up to $\sim 14.0 \mathrm{~m} \mathrm{~s}^{-1}$, with corresponding wind variance of $\sim 13.7$ and $10.3 \mathrm{~m}^{2} \mathrm{~s}^{-2}$ at Gangavaram and Kakinada, respectively (Fig. 5 b.2 and c.2). The wind direction stabilised and remained north-easterly (Fig. 5b.3 and c.3, Table 3) during E2 at Gangavaram and Kakinada. The atmospheric pressure (Fig. 5a.4-c.4) shows a variance of $\sim 2.7 \mathrm{mb}^{2}$ and is devoid of any noticeable fall during E2 at Gopalpur, Gangavaram and Kakinada. Similarly, the anoma- 
Table 3. Meteorological and sea level observations at Gopalpur, Gangavaram and Kakinada during E2 from 26-31 December 2011.

\begin{tabular}{cllll}
\hline Sr No & Variables & Gopalpur & Gangavaram & Kakinada \\
\hline 1 & Sea level residual (SLR in cm) & $27.4^{\mathrm{a}}$ & $26.5^{\mathrm{a}}$ & 32.9 \\
2 & SLR rise time from zero-maxima (h) & - & - & 123.8 \\
3 & SLR fall time from maxima-zero (h) & - & - & 233.25 \\
4 & Maximum wind speed $\left(\mathrm{m} \mathrm{s}^{-1}\right)$ & 6.1 & 15.0 & 13.3 \\
5 & Wind direction (degrees) & $184^{\mathrm{b}}$ & 41.9 & 60.9 \\
6 & Air temperature reduction in range $\left({ }^{\circ} \mathrm{C}\right)$ & $10.1-2.6$ & $8.4-3.1$ & $8.5-2.6$ \\
7 & Relative humidity range reduction $(\%)$ & $65.7-27.0$ & $57.8-23.8$ & $46-13.6$ \\
\hline
\end{tabular}

a Maximum of the SLR oscillation at Gopalpur and Gangavaram. ${ }^{\mathrm{b}}$ The direction fluctuated during E2 and stabilised to

$\sim 184^{\circ}$ with respect to the north after 5 January 2012 and maintained this direction till 10 January 2012.

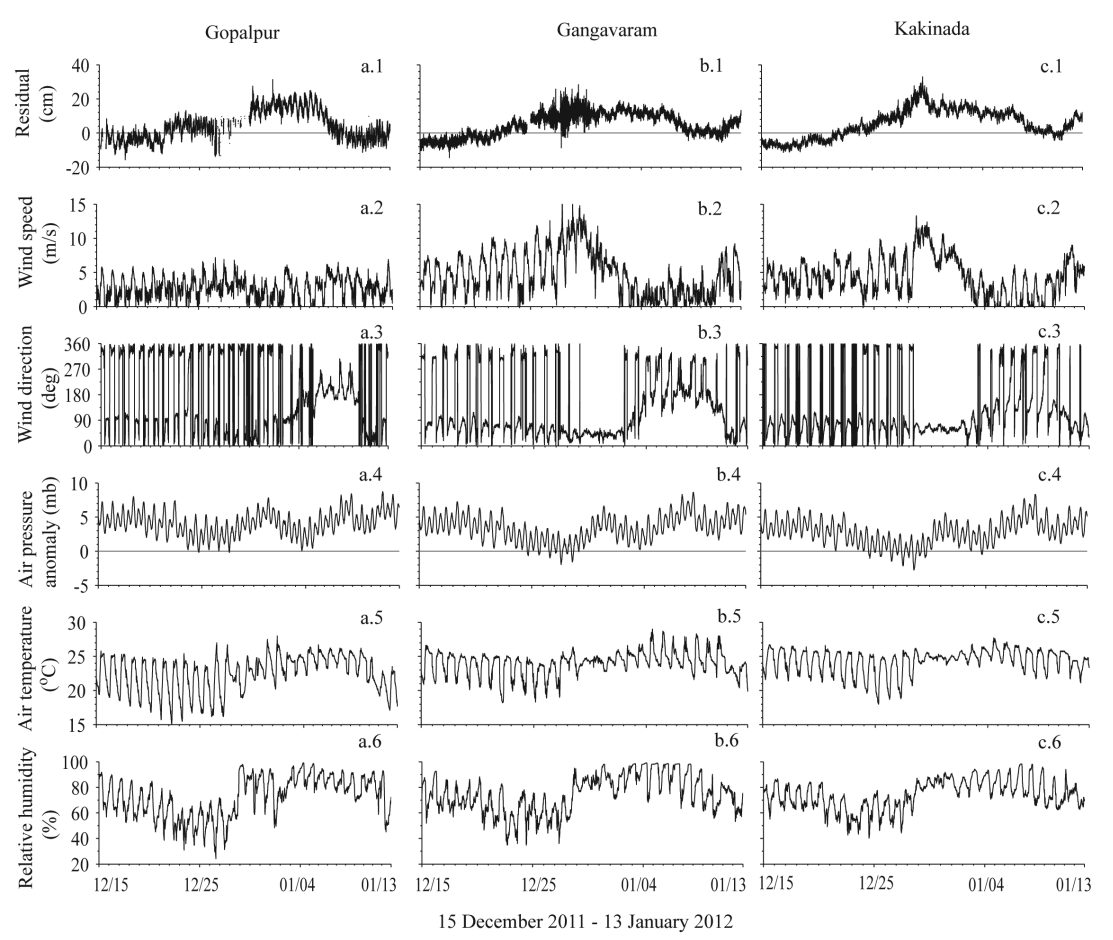

Figure 5. Sea level residual and surface meteorological parameters during the episodic event E2. (a.1 to a.6) SLR, wind speed, wind direction, atmospheric pressure anomaly, air temperature and relative humidity at Gopalpur, Odisha. (b.1 to b.6) same as in (a) at Gangavaram, Andhra Pradesh. (c.1 to c.6) same as in (a) at Kakinada, Andhra Pradesh. The atmospheric pressure anomaly is estimated by subtracting the mean atmospheric pressure (1 September 2011 to 31 January 2012) from the measured atmospheric pressure for respective stations.

lous variations in temperature due to $\mathrm{E} 2$ are not observed; however, the range is narrowed down from $\sim 9.0$ to $2.7^{\circ} \mathrm{C}$ at the three stations (Fig. 5a.5-c.5). Similarly, a reduction in relative humidity range is also observed at the three stations in the BOB (Fig. 5a.6-c.6, Table 3).

\section{Regression model}

Multi-linear regression analysis of SLR as the dependent variable with wind stress components $\left(\tau_{U}, \tau_{V}\right)$ and atmospheric pressure $\left(A_{P}\right)$ as the independent variable is performed as explained in Sect. 2 (Eq. 1). How well the model describes the sea level residual is assessed by looking at the percentage of sea level variance explained $\left(\operatorname{Var}_{\mathrm{e}}\right)$ by the model.

$\operatorname{Var}_{\mathrm{e}}=\left(1-\frac{\operatorname{variance}(\varepsilon)}{\text { variance }(\text { measured SLR })}\right) \times 100$

The multi-linear regression performed with 10, $60 \mathrm{~min}, 6,12$ and $24 \mathrm{~h}$ averaged data of Verem and Karwar is shown in the Supplement (Figs. S1-S5) along with the SLR variance (Table S1). The daily average of estimated SLR is comparable with the daily average of measured SLR, and it is able to account for the low frequency variations in the SLR during the 


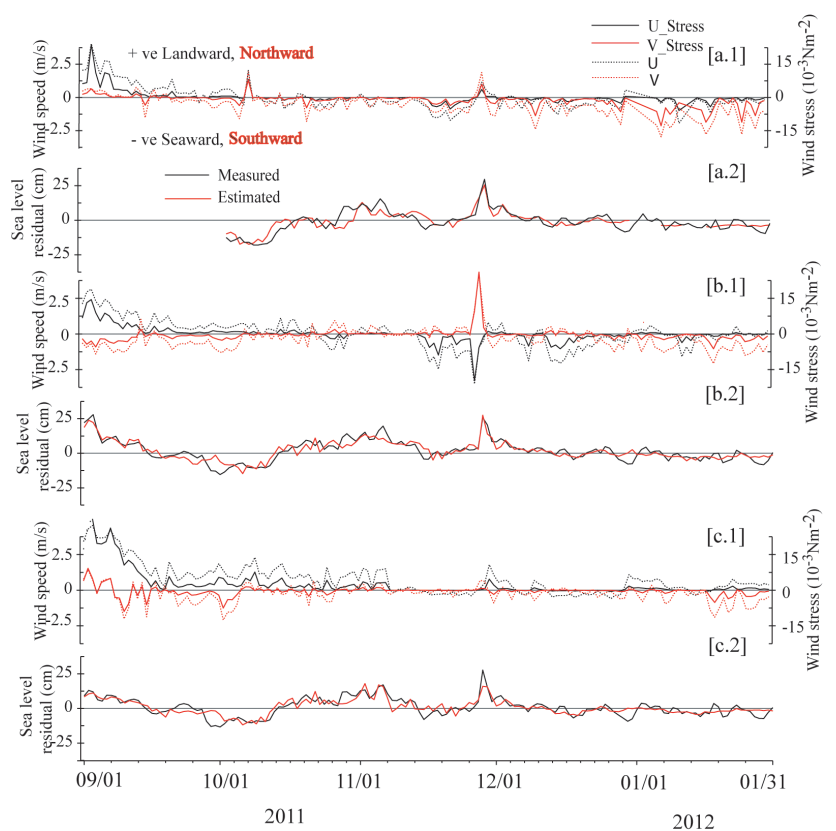

Figure 6. Daily mean wind, wind stress, measured sea level residual and estimated sea level residual from September 2011 to January 2012 at (a) Ratnagiri, (a.1) daily averaged cross-shore (black) and along-shore (red) winds stress along with respective winds (dotted black or red), (a.2) daily mean measured sea level residual (black) and estimated residual (red); (b) Verem, (b.1) and (b.2) same as in (a); (c) Karwar, (c.1) and (c.2) same as in (a). Daily mean estimated SLR is obtained using the multi-linear regression method using daily mean cross-shore $\left(\tau_{U}\right)$, along-shore $\left(\tau_{V}\right)$ components of winds stress and atmospheric pressure $\left(A_{P}\right)$ as independent variables.

study period of 5 months (September 2011 to January 2012). Therefore, in this section daily averaged data series of SLR and AWS is used to perform multi-linear regression. To begin with, multi-linear regression is performed with cross-shore $\left(\tau_{U}\right)$, along-shore $\left(\tau_{V}\right)$ components of winds stress and atmospheric pressure $\left(A_{P}\right)$ individually as independent variable to regress the SLR. This would enable us to know, the contribution to the SLR variability by the various surface meteorological variables individually. Then all the three independent variables $\left(\tau_{U}, \tau_{V}, A_{P}\right)$ together are used to regress the daily mean SLR. Results are listed in Table 4 and plotted in Figs. 6 and 7. The cross- and along-shore components are estimated using the local shoreline angles with respect to the north from Google Earth. In AS, the local shoreline angle estimated at Ratnagiri, Verem and Karwar with respect to the north is $\sim-12,-27$ and $-19^{\circ}$, respectively. Similarly, in the BOB the local shoreline angle with respect to the north is $\sim 52,45$ and $50^{\circ}$ at Gopalpur, Gangavaram and Kakinada, respectively. The variations in $\tau_{U}, \tau_{V}$ and $A_{P}$ results in the SLR variability. The relation between atmospheric pressure and sea level is $\sim-1 \mathrm{~cm} \mathrm{mb}^{-1}$, inverse barometric effect. The cross-shore wind $(U)$ towards land (sea) will give rise

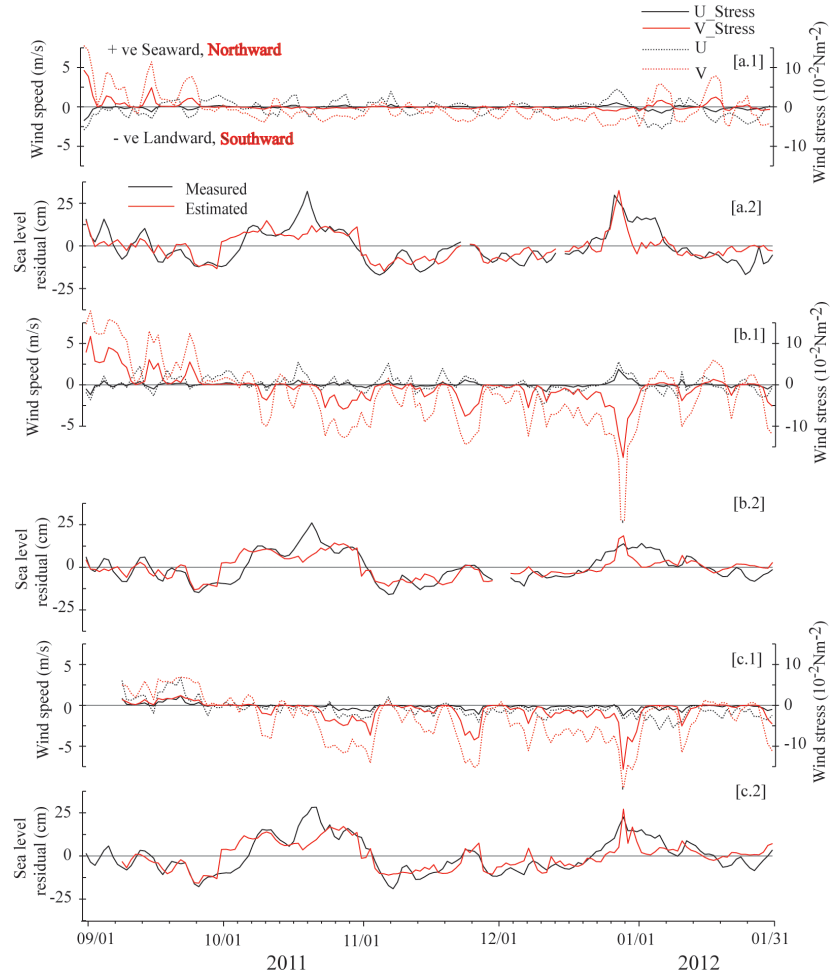

Figure 7. Daily mean wind, wind stress, measured sea level residual and estimated sea level residual from September 2011 to January 2012 at (a) Gopalpur, (a.1) daily averaged cross-shore (black) and along-shore (red) winds stress along with respective winds (dotted black or red), (a.2) daily mean measured sea level residual (black) and estimated residual (red); (b) Gangavaram, (b.1) and (b.2) same as in (a); (c) Kakinada, (c.1) and (c.2) same as in (a). Daily mean estimated SLR is obtained using the multi-linear regression method using daily mean cross-shore $\left(\tau_{U}\right)$, along-shore $\left(\tau_{V}\right)$ components of winds stress and atmospheric pressure $\left(A_{P}\right)$ as independent variables.

to increase (decrease) in SLR due to wind stress. Since the study region is in the Northern Hemisphere, the along-shore northward winds with the coast at their right will increase the sea level due to Coriolis force. Therefore, in the AS the positive (negative) $U$ and $V$ will increase (decrease) the SLR (Fig. 6) and in the BOB the positive (negative) $U$ and $V$ will decrease (increase) the SLR (Fig. 7).

At all the three study locations in $\mathrm{AS}, \tau_{U}, \tau_{V}$ and $A_{P}$ individually could explain an average $45 \%$ SLR variability; when $\tau_{U}, \tau_{V}$, and $A_{P}$ together are used to regress the daily mean SLR, the total $\operatorname{Var}_{\mathrm{e}}$ is $\sim 69 \%$ (Table 4 ). Daily mean $U\left(\tau_{U}\right), V\left(\tau_{V}\right)$ and estimated SLR obtained from independent variables $\left(\tau_{U}, \tau_{V}, A_{P}\right)$ for Ratnagiri is plotted in Fig. 6a. It is observed that the estimated daily mean SLR during E1 is able to peak at up to $96.3 \%$ of the measured daily mean SLR (Fig. 6a.2 and Table 5). The monthly $\operatorname{Var}_{\mathrm{e}}$ is $\sim 50 \%$ during October and December 2011 (Table 4 and Fig. 8a). However, when E1 occurred in November 2011, $\tau_{U}, \tau_{V}$, and $A_{P}$ to- 
Table 4. The daily mean sea-level variability explained $\left(\operatorname{Var}_{\mathrm{e}}\right)$ by linear $\left(\tau_{U}, \tau_{V}, A_{P}\right.$ individually) and multi-linear $\left(\tau_{U}, \tau_{V}, A_{P}\right.$ together) regression during different months from September 2011 to January 2012.

\begin{tabular}{|c|c|c|c|c|c|c|c|}
\hline \multirow[t]{2}{*}{ Station } & \multirow[t]{2}{*}{ Variable } & \multirow[t]{2}{*}{ Total $\operatorname{Var}_{\mathrm{e}}(\%)$} & \multicolumn{5}{|c|}{ Monthly $\operatorname{Var}_{\mathrm{e}}(\%)$} \\
\hline & & & Sep & Oct & Nov & Dec & Jan \\
\hline \multicolumn{8}{|c|}{ Arabian Sea } \\
\hline \multirow[t]{2}{*}{ Ratnagiri } & $\tau_{U}, \tau_{V}, A_{P}$ & $43.9,45.0,59.3$ & & & & & \\
\hline & $\tau_{U}, \tau_{V}, A_{P}$ & 68.4 & & 52.6 & 67.8 & 46.7 & 3.4 \\
\hline \multirow[t]{2}{*}{ Verem } & $\tau_{U}, \tau_{V}, A_{P}$ & $48.9,39.8,58.2$ & & & & & \\
\hline & $\tau_{U}, \tau_{V}, A_{P}$ & 73.9 & 85.3 & 72.9 & 54.5 & 42.6 & 7.0 \\
\hline \multirow[t]{2}{*}{ Karwar } & $\tau_{U}, \tau_{V}, A_{P}$ & $37.3,29.5,45.2$ & & & & & \\
\hline & $\tau_{U}, \tau_{V}, A_{P}$ & 64.8 & 64.0 & 75.7 & 56.7 & 38.8 & 8.3 \\
\hline \multicolumn{8}{|c|}{ Bay of Bengal } \\
\hline \multirow[t]{2}{*}{ Gopalpur } & $\tau_{U}, \tau_{V}, A_{P}$ & $43.2,40.1,31.2$ & & & & & \\
\hline & $\tau_{U}, \tau_{V}, A_{P}$ & 53.4 & 58.8 & 8.3 & 44.1 & 74.7 & 10.2 \\
\hline \multirow[t]{2}{*}{ Gangavaram } & $\tau_{U}, \tau_{V}, A_{P}$ & $42.0,47.6,44.2$ & & & & & \\
\hline & $\tau_{U}, \tau_{V}, A_{P}$ & 56.6 & 64.4 & 14.2 & 37.1 & 64.3 & 11.6 \\
\hline \multirow[t]{2}{*}{ Kakinada } & $\tau_{U}, \tau_{V}, A_{P}$ & $49.4,55.6,44.4$ & & & & & \\
\hline & $\tau_{U}, \tau_{V}, A_{P}$ & 62.1 & 77.8 & 15.4 & 58.0 & 68.1 & 17.7 \\
\hline
\end{tabular}

gether are able to explain the SLR variability up to $\sim 68 \%$. In January 2012, the $\operatorname{Var}_{\mathrm{e}}$ is less than $20 \%$ at all the sites in the AS and the BOB (Fig. 8a and Table 4). At Verem (Fig. 6b), the total $\operatorname{Var}_{\mathrm{e}}$ is highest among all the locations in AS, when $\tau_{U}, \tau_{V}$, and $A_{P}$ together are used to estimate the daily mean SLR as presented in Fig. 6b.2. During E1, the $-U(V)$ will tend to decrease (increase) the sea level at Verem (Fig. 6b.1), still the estimated daily mean SLR is able to reproduce the comparable response with measured daily mean SLR, with a minor overshoot by $\sim 6.5 \%$ (Table 5). At Karwar also the $U(-V)$ will tend to increase (decrease) the sea level during E1 (Fig. 6c.1); however, the estimated SLR is able to peak only at up to half of the measured daily mean SLR (Fig. 6c.2 and Table 5).

In the $\mathrm{BOB}$, the $\tau_{U}, \tau_{V}$ and $A_{P}$ individually could explain an average $44 \%$ SLR variability, when $\tau_{U}, \tau_{V}$, and $A_{P}$ together are used to regress the daily mean SLR, the total $\operatorname{Var}_{\mathrm{e}}$ is $\sim 57 \%$ (Table 4). The monthly $\operatorname{Var}_{\mathrm{e}}$ is low $<20 \%$ in October and January for all the three stations in the BOB as shown in Fig. 8b. In the BOB, the daily mean $U\left(\tau_{U}\right)$, $V\left(\tau_{V}\right)$ and estimated SLR is plotted in Fig. 7 for Gopalpur, Gangavaram and Kakinada. As stated earlier, along the east coast of India in the BOB, the positive (negative) $U$ and $V$ will decrease (increase) the sea level. Figure 7 a.1 shows the $U(-V)$ at Gopalpur, which are seaward (southward) during E2 favouring the sea-level fall (rise) due to the surface stress. However, by 1 January 2012 both the cross- and along-shore component of wind $-U(V)$ turns landwards (northwards), imposing a sea-level rise (fall). Sea-level appears to be influenced more by alongshore wind, where the estimated SLR follows the forcing $\left(\tau_{V}\right)$ of $V$. Figure $7 \mathrm{a} .2$ is plotted with the estimated and measured daily mean SLR at Gopalpur, dur- ing E2 the estimated SLR is comparable and is $\sim 9 \%$ more than the measured daily mean SLR (Table 5). It is also observed that the measured SLR remains high $(\sim 15 \mathrm{~cm})$ till 5 January 2012, whereas the estimated SLR falls to zero by 31 December 2011. At Gangavaram, the $U\left(\tau_{U}\right) V\left(\tau_{V}\right)$ winds (wind stress) are plotted in Fig. 7b.1, where the daily mean along-shore $(V)$ winds are observed to dominate with a range of $\sim \pm 10 \mathrm{~m} \mathrm{~s}^{-1}$. During E2, the measured (estimated) daily mean SLR peaks at up to $13.8(18.5) \mathrm{cm}$; the estimate overshoots by $\sim 34 \%$ (Table 5). At Gangavaram, the rise in SLR residual is predominantly due to high along-shore wind $(-V)$, as explained by $\operatorname{Var}_{\mathrm{e}}$ for December 2011 which is $64 \%$. Also the measured daily mean SLR remained high from 22 December 2011 to 9 January 2012, whereas the estimated SLR remained high from 25 December 2011 to 2 January 2012 (Fig. 7b.2). Similarly, at Kakinada also the $V$ winds (Fig. 7c.1) appears to dominate with peaks at up to $\sim-10 \mathrm{~m} \mathrm{~s}^{-1}$. During E2, the measured (estimated) daily mean SLR peaked at up to $22.3(27.1) \mathrm{cm}$; the estimate overshoots by $21 \%$ (Table 5). At Kakinada, the rise in sea level residual is predominantly due to strong southward wind $(V)$. The measured SLR started rising above zero on 23 December, reached highest level on 29 December and descended by 9 January 2012, whereas the estimated SLR started ascending on 25 December, reached the highest level on 29 December 2011 and then dropped to zero level by 4 January 2012 (Fig. 7c.2).

\section{High frequency response and harbour resonance}

Harbour oscillations (coastal seiches) as explained by Rabinovich (2009) are specific type of seiche motion that occur in 
Table 5. The peak response of the daily mean sea level residual (SLR) along with the estimated daily mean SLR during E1 \& E2.

\begin{tabular}{lcrrr}
\hline & & $\begin{array}{r}\text { Measured daily- } \\
\text { mean peak } \\
\text { SLR }(\mathrm{cm})\end{array}$ & $\begin{array}{r}\text { Estimated } \\
\text { daily mean } \\
\text { SLR peak }(\mathrm{cm})\end{array}$ & $\begin{array}{r}\text { Difference } \\
(\%)\end{array}$ \\
\hline Ratnagiri & E1 & 29.6 & 28.5 & 3.7 \\
Verem & E1 & 25.8 & 27.4 & -6.5 \\
Karwar & E1 & 27.7 & 13.6 & 50.9 \\
Gopalpur & E2 & 29.7 & 32.4 & -8.9 \\
Gangavaram & E2 & 13.8 & 18.5 & -34.1 \\
Kakinada & E2 & 22.3 & 27.1 & -21.5 \\
\hline
\end{tabular}

partially enclosed basins (bays, fjords, inlets and harbours) and are connected through one or more openings to the sea. They are mainly generated by the long waves entering through the open boundary (harbour entrance) from the open sea. An another important property of harbour oscillations is that even small vertical motions (sea level oscillations) may be accompanied by large horizontal motions (harbour currents), resulting in increased risk of damage of moored ships, breaking mooring lines as well as affecting various harbour procedures (Rabinovich, 2009). These waves are similar to a tsunami; however, the catastrophic effects are normally observed in specific bays and inlets. Some specific sites, that have favourable conditions for the resonant generation of extreme ocean waves regularly, have been listed by Monserrat et al. (2006), Rabinovich (2009) and Joseph (2011). Similar phenomena occurs on the southern west coast of India, mainly during pre-southwest monsoon during April or May (Kurian et al., 2009).

In order to understand the harbour oscillations induced by tropical cyclones at various locations, the SLRs are high-pass filtered (time period $\leq 2 \mathrm{~h}$ ) using a 5 th order Butterworth filter (Fig. 9). The amplitude of high frequency SLR (hfSLR) oscillations in response to E1 at Ratnagiri is $\sim \pm 10 \mathrm{~cm}$ (Fig. 9a), less at Verem and Karwar (Fig. 9b and c). The Karwar station is located in open ocean and therefore does not have the resonance features of a harbour. However, the Verem station is located in Mandovi estuary and Ratnagiri station is located in a cove and may experience resonance with meteorological disturbances. In a similar study at Verem, Mehra et al. (2012) reported the hf-SLR oscillations of $\sim \pm 15$ (10) $\mathrm{cm}$ in response to the Cyclone Yemyin (Phyan) which occurred in the BOB (the AS) during 23-25 June 2007 (9-12 November 2009). The hf-SLR oscillations at Tuticorin (Mandapam) are up to 10 (5) cm during E1 (Fig. 9d and e). Mandapam sea level gauge is located on the common boundary of Palk Strait and the Gulf of Mannar, whereas the Tuticorin sealevel gauge is located in the Gulf of Mannar (Fig. 1). The hf-SLR oscillations at the stations located in the BOB are also shown in Fig. 9. The hf-SLR amplitude due to E2 at Tuticorin, Mandapam is not observable, and at Gopalpur a brief amplitude of $10 \mathrm{~cm}$ is observed (Fig. 9d, e and f). At Gan-

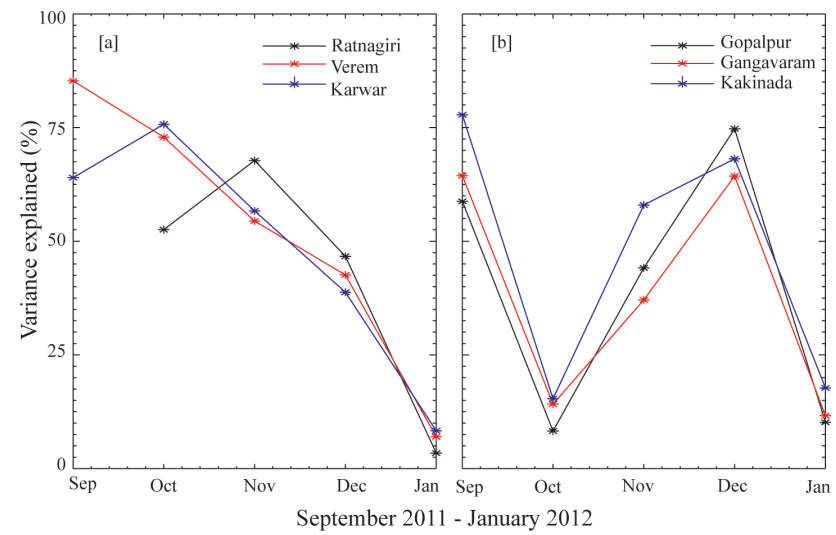

Figure 8. Daily mean sea-level variability explained $\left(\operatorname{Var}_{\mathrm{e}} \%\right)$ by the multi-linear regression during different months from September 2011 to January 2012. (a) Vare (\%) at Ratnagiri (black), Verem (red) and Karwar (blue). (b) $\operatorname{Var}_{\mathrm{e}}(\%)$ at Gopalpur (black), Gangavaram (red) and Kakinada (blue).

gavaram (Kakinada) the hf-SLR variations are $\sim \pm 10(5) \mathrm{cm}$ as both the gauges are located in the harbour (Fig. $9 \mathrm{~g}$ and $\mathrm{h}$ ), and $\sim \pm 4 \mathrm{~cm}$ at Port Blair (Fig. 9i).

Event E1 and background SLR spectra estimated at Karwar, Verem and Ratnagiri are indicated in Fig. 10. The spectrum of SLR data is obtained using "pwelch" function from MATLAB with Hamming window of 256 data points and $50 \%$ overlap. Rabinovich (1997) proposed an approach to separate the influence of source and topography in observed tsunami spectra. The method assumed a linear tide gauge response to external forcing and is based on comparative analysis of tsunami and background spectra. This method will be used to understand the resonant influence of local topography and spectral characteristics of SLR during an event at a particular location. The data duration for estimating the spectrum of the SLR during E1 (background) is from 26 November to 1 December (1 September to 20 November) 2011. Similarly, the data duration during the event E2 (background) is 25-31 December (1 September-10 December) 2011, respectively. 


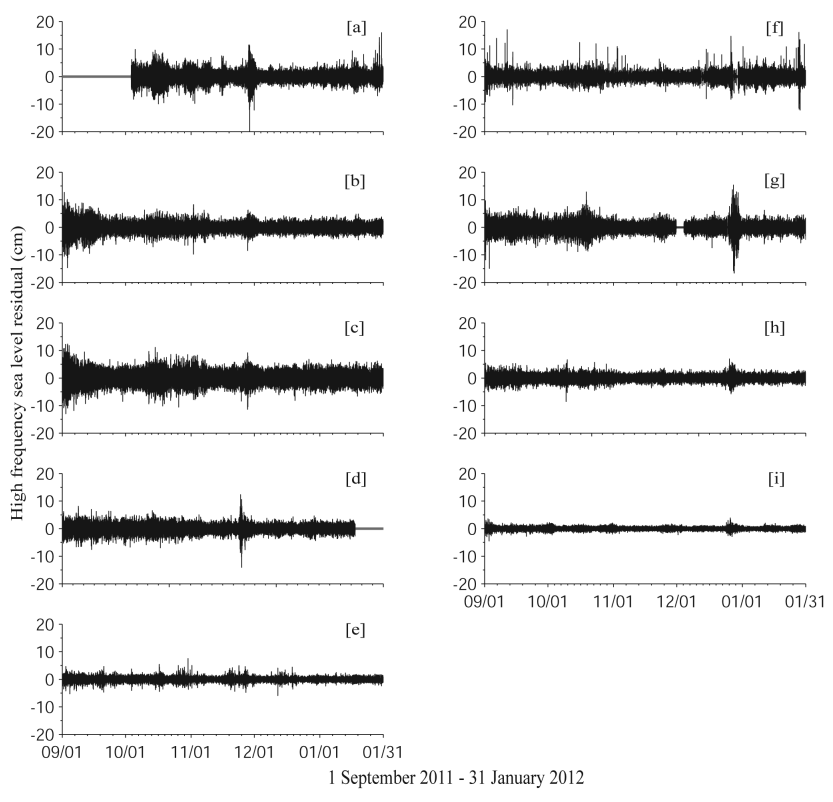

Figure 9. High-pass filtered sea-level residual (hf-SLR) using a 5 th order Butterworth filter (time period $\leq 2 \mathrm{~h}$ ) at (a) Ratnagiri, (b) Verem, (c) Karwar, (d) Tuticorin, (e) Mandapam, (f) Gopalpur, (g) Gangavaram, (h) Kakinada and (i) Port Blair.

The background spectra of different sites have significant differences at high frequencies as seen in Fig. 10, indicating the influence of local topography. The event spectrum at Ratnagiri is high in energy, well lifted above that of background with major peaks at 127, 80, 47, 30, 26 and $14 \mathrm{~min}$ during E1 as shown in Fig. 10a. At Verem the event spectra is intertwined with background spectra with peaks at 182, 91, 40 and $20 \mathrm{~min}$ as shown in Fig. 10b. However, the event spectrum at Verem was energetic during the cyclone Yemyin (2007), September Sumatra Tsunami (2007), and the cyclone Phyan (2009), where a distinct peak was observed at $\sim 43$ min (Mehra et al., 2012). Similarly, the event spectrum during E1 (Fig. 10c) at Karwar is similar to the background with some detectable peaks at 106, 67, 44 and $21 \mathrm{~min}$, and further higher frequencies are merged with the background spectra, indicating open-ocean behaviour (lack of harbour resonance). The influence of E1 is also visible at Tuticorin with dominant spectral peaks at 106, 53, 44, 24 and $18 \mathrm{~min}$ (Fig. 10d). However, at Mandapam (Fig. 10e) the event spectra are intertwined with background spectra with peaks at 116, 80, 42 and $26 \mathrm{~min}$.

Event E2 and background SLR spectra estimated at Gopalpur, Gangavaram, Kakinada, and Port Blair during E2 are shown in Fig. 11. The event spectrum during E2 (Fig. 11a) at Gopalpur is intertwined with the background spectra with some detectable peaks at 106, 80, 60, 45, 36, 21 and $12 \mathrm{~min}$. The spectral peak at 45 and $21 \mathrm{~min}$ are also present in the background signal. The event spectral energy at Gangavaram (Fig. 8b) is higher compared to the back-
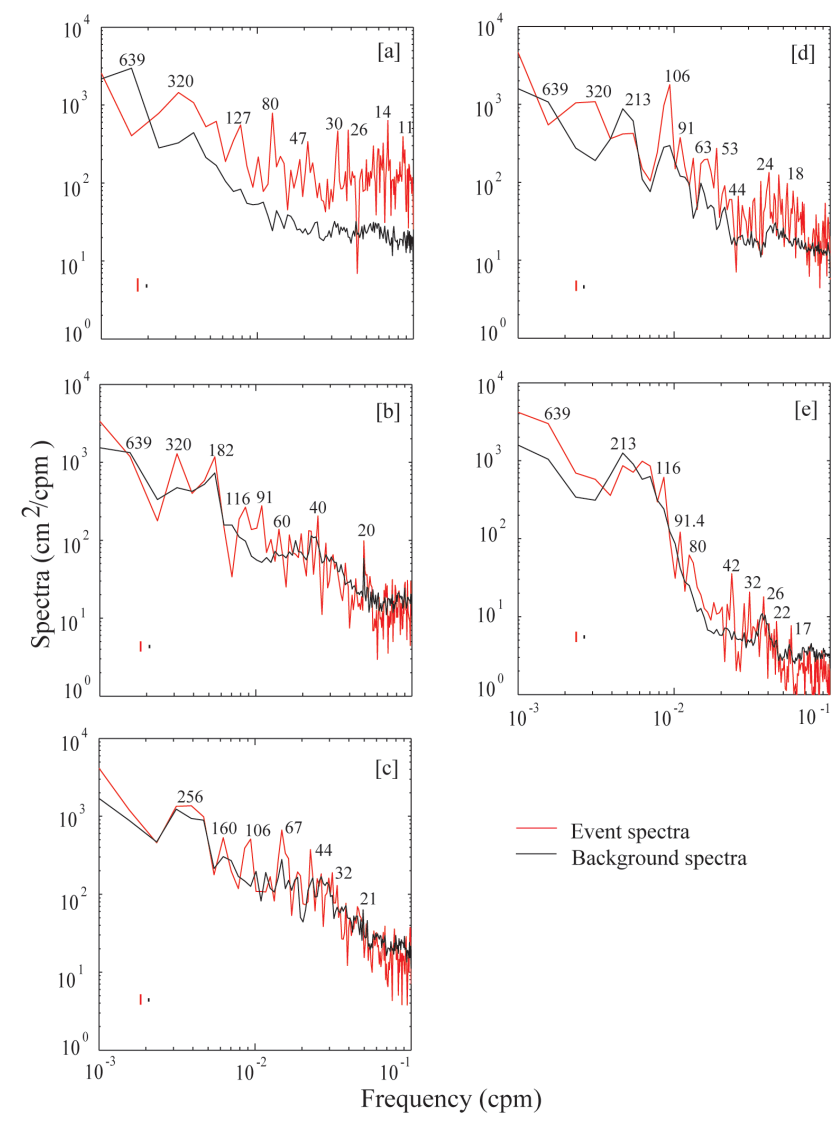

Figure 10. Spectrum of sea level residual (SLR) during E1 at (a) Ratnagiri, (b) Verem, (c) Karwar, (d) Tuticorin and (e) Mandapam. The data duration for estimating the spectrum of the SLR during E1 (background) is from 26 November to 1 December (1 September to 20 November) 2011. Vertical red (black) line shows the $95 \%$ confidence interval of the event (background) spectrum for the respective stations.

ground SLR spectra with peaks at 213, 98, 67, 41, 25 and $18 \mathrm{~min}$; however, the background spectra shows peaks at $\sim 128,98$ and $17 \mathrm{~min}$. The phenomena of harbour resonance is clearly visible at Gangavaram station (Fig. 5b.1), where it is not the surge but high frequency oscillations triggered by the long waves arriving from the open ocean. At Kakinada (Fig. 11c) the spectra for lower frequencies (time period $>41 \mathrm{~min}$ ) are similar, but the energy is enhanced for higherfrequency (shorter time-period) oscillations with time periods 41,37, 25 and $12 \mathrm{~min}$, suggesting resonance occurring in the harbour. At Port Blair, the SLR spectra of both the event and background show similar variability with event peaks at 160, 85, 47, 41, 26 and $17 \mathrm{~min}$ (Fig. 11d). The background SLR spectrum has noticeable peaks at 41 and $26 \mathrm{~min}$. Event spectra at shorter time periods are marginally above the background spectra, which indicates the absence of harbour resonance as Port Blair station provides open-ocean conditions. 


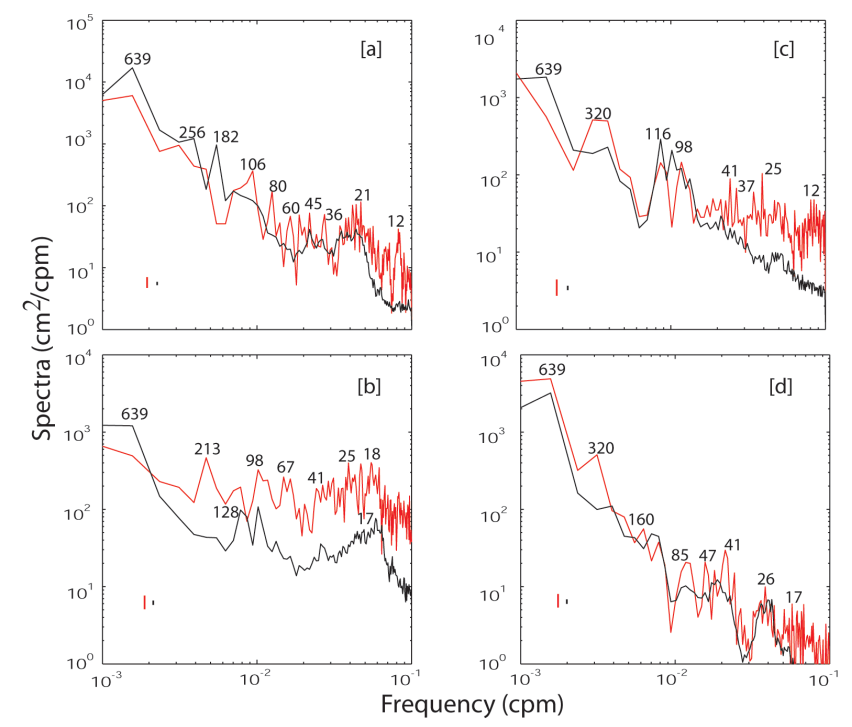

Figure 11. Spectrum of sea level residual (SLR) during E2 at (a) Gopalpur, (b) Gangavaram, (c) Kakinada and (d) Port Blair. The data duration for estimating the spectrum of the SLR during E2 (background) is 25-31 December (1 September-10 December) 2011. Vertical red (black) line shows the $95 \%$ confidence interval of the event(background) spectrum for the respective stations.

\section{Results and discussion}

We summarise the response of sea level of the two events in the AS and the BOB. The SLR rise (fall) in the AS due to E1 reflects the winds as is also seen in the estimated SLR. The estimated SLR peak value at Ratnagiri and Verem is comparable to the measured SLR during E1 but at Karwar it is short by $\sim 50 \%$. The $\operatorname{Var}_{\mathrm{e}}$ accounted by local surface meteorological parameters is $\sim 69 \%$. Var $_{\mathrm{e}}$ is small in January at all the locations of the present study (Table 4). In a similar study by Mehra et al. (2010), multi-linear regression analysis (each with a 2-month duration) was also used to resolve the dependence of sea level on various forcing parameters for 2007 and 2008 at Verem, Goa. During the summer monsoon (May-September), the sea level variability attributable to wind was up to 47 and $75 \%$, respectively, for 2007 and 2008; however, it decreased to $<20 \%$ during the winter monsoon (November-February). A significant part of the variability observed in sea level remains unaccounted for and was attributed to remote forcing. In the BOB, the SLR response to E2 is of a plateau shape with rising peaks and prolonged falls during E2, which the estimated SLR is not able to capture. This persistence of high daily mean SLR state may be attributed to intensity, direction and duration of the event, the distance from the source etc. The distance of Thane (E2) track is $\sim 570 \mathrm{~km}$ from Gangavaram as shown in Fig. 1 . The slope of the continental shelf will also affect the level of surge in a particular area. For example areas with shallow slopes of the continental shelf (as in AS) will allow a greater storm surge, and areas with deep water just offshore experience large waves, but little storm surge (SLOSH, 2003). At Gangavaram, the daily mean SLR is low $(\sim 13.8 \mathrm{~cm}) \mathrm{com}-$ pared to the other sites on the east coast of India (Table 5), and this could be attributed to distinct harbour oscillations at this location (Fig. 5b.1). Also note that when Thane crossed the Tamil Nadu coast just south of Cuddalore between 01:00 and 02:00 UTC of 30 December 2011, no distinct surge is observed at Mandapam and Tuticorin, even though Mandapam (Tuticorin) is in close proximity $\sim 237$ (360) $\mathrm{km}$ to Thane track. The highest surges usually occur to the right of the storm track (travelling with the storm) at approximately the radius of maximum wind whereas Mandapam and Tuticorin were to the left of the track.

Storm surge is generated partly by the atmospheric pressure variations, but the main contributing factor is wind acting over the shallow water and it is an air-sea interaction problem. The basic mechanism involved in the generation of coastal surges is the influence of a long-shore wind stress, driving an Ekman transport towards the coast, causing the piling-up of water within a Rossby radius of deformation. Only the long-shore wind stress and atmospheric pressure variations associated with a cyclone generate a surge (Thomson, 1970). The surge travels along the coast as a Kelvin wave, away from the finite area of forcing, at a speed $c=$ $\sqrt{ }(g h)$, where $g$ is the acceleration due to gravity and $h$ is the depth. Such coastally trapped motions (with the coast to the right (left) in the Northern (Southern) Hemisphere) are called forced Kelvin waves (e.g. LeBlond and Mysak, 1978; Gill, 1982). In the spectrum, the storm surges are centred about $10^{-4} \mathrm{~Hz}$, which corresponds to a period of about $3 \mathrm{~h}$ (Platzman, 1971). A few parameter estimates of the E1 and $E 2$ are listed in Table 6 . To estimate the surge propagation speed, we have also added a few more locations, where hourly sea level data are available from www.gloss-sealevel.org (marked as red star in Fig. 1). Figure 12 shows the sea level response from Colombo, Sri Lanka to Jask, Iran in the Indian Ocean. Some relevant parameters of the storm surge are listed in $\mathrm{Ta}-$ ble 7 . The average surge propagation speed is estimated to be $\sim 6.5 \mathrm{~m} \mathrm{~s}^{-1}$. The E1 moved northwards with an average along-shore speed of $\sim 6.2 \mathrm{~m} \mathrm{~s}^{-1}$, with the track almost parallel to the west coast of India. The match of the surge propagation speed of $6.5 \mathrm{~m} \mathrm{~s}^{-1}$ with that of E1 alongshore speed is evidence of a forced wave. The residual surge lagged the storm by 3, 4, 6.5 and $8.5 \mathrm{~h}$ (Fig. 1 and Table 7) to its nearest proximity at Colombo, Kochi, Karwar and Verem, respectively, with constant peak amplitude of $\sim 34.6 \mathrm{~cm}$ (Fig. 12). However, at Kochi, the development of secondary peak is clearly visible with time difference of $\sim 14 \mathrm{~h}$ between the two peaks of $\sim 13.5 \mathrm{~cm}$. At Ratnagiri and Karachi the surge peak leads the storm by $\sim 1 \mathrm{~h}$ with the constant peak amplitude of $\sim 33.5 \mathrm{~cm}$.

Similar response as above was observed by Fandry et al. (1984), when Cyclone Glynis moved slowly and almost parallel to the western coast of Australia in February 1970. In 
Table 6. Parameter estimates of the events E1 and E2.

\begin{tabular}{|c|c|c|c|c|c|c|}
\hline Name & Duration & $\begin{array}{r}\text { Average eastward } \\
\text { velocity } \\
U_{m}\left(\mathrm{~m} \mathrm{~s}^{-1}\right)\end{array}$ & $\begin{array}{r}\text { Average northward } \\
\text { velocity } \\
V_{m}\left(\mathrm{~m} \mathrm{~s}^{-1}\right)\end{array}$ & $\begin{array}{r}\text { Minimum } \\
\text { coastal pressure } \\
P_{\mathrm{c}}(\mathrm{mb})\end{array}$ & $\begin{array}{r}\text { Maximum } \\
\text { winds } \\
V\left(\mathrm{~m} \mathrm{~s}^{-1}\right)\end{array}$ & $\begin{array}{r}\text { Maximum } \\
\text { stress } \tau_{m} \\
\left(\mathrm{~N} \mathrm{~m}^{-2}\right)\end{array}$ \\
\hline $\mathrm{DD}(\mathrm{E} 1)$ & 26 Nov-1 Dec 2011 & 1.1 & 6.2 & 998 & 17 & 0.9 \\
\hline Thane (E2) & 25-31 Dec 2011 & -1.1 & 0.3 & 969 & 40.8 & 5.2 \\
\hline
\end{tabular}

Note: $V=3.44\left(1000-P_{\mathrm{c}}\right)^{0.644}$ and $\tau_{m}=0.000314 V^{2}$ (refer Fandry et al., 1984). $P_{\mathrm{c}}$ is minimum central pressure.

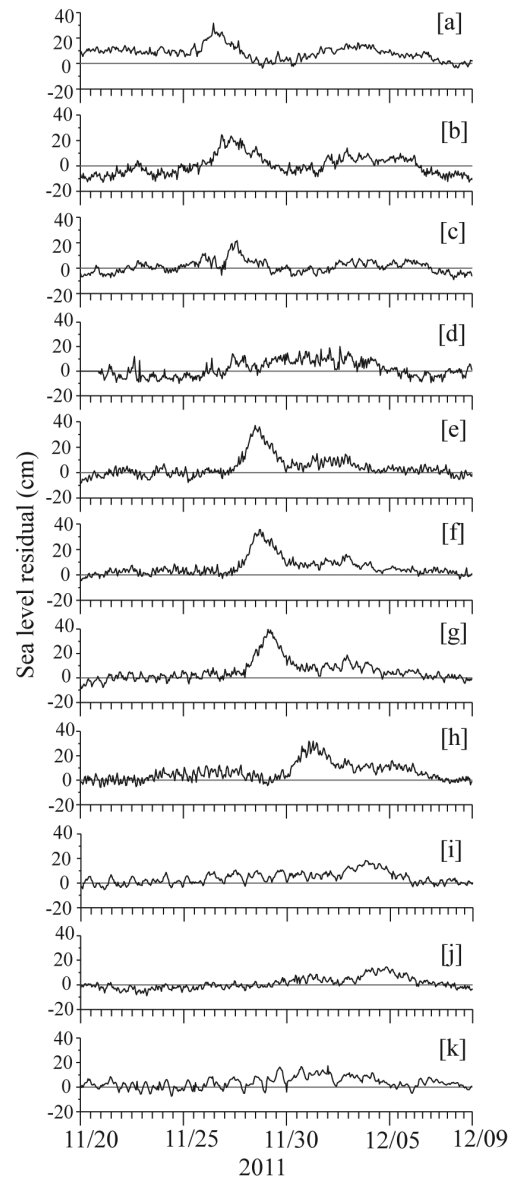

Figure 12. Hourly sea level residual at (a) Colombo, (b) Mandapam, (c) Tuticorin, (d) Kochi, (e) Karwar, (f) Verem, (g) Ratnagiri, (h) Karachi, (i) Chabahar, (j) Jask and (k) Masirah. Note: 1 - Sea level residual data at Mandapam, Tuticorin, Karwar, Verem and Ratnagiri is hourly averaged. 2 - Sea level data at Colombo, Kochi, Karachi, Chabahar, Jask and Masirah is at hourly interval and downloaded from www.gloss-sealevel.org.

this event, a strong coastal peak travelled down the coast well ahead of the cyclone. In this example $\mu>\frac{U_{m} f}{C}$ and $V_{m}<c$ (where $f$ is Coriolis parameter, $U_{m}\left(V_{m}\right)$ is eastward (northward) velocity of cyclone and $\mu$ is decay rate, and theory predicts a coastal peak of constant amplitude moving ahead of the cyclone. In their study, they characterised the sea level response to tropical cyclone as follows:

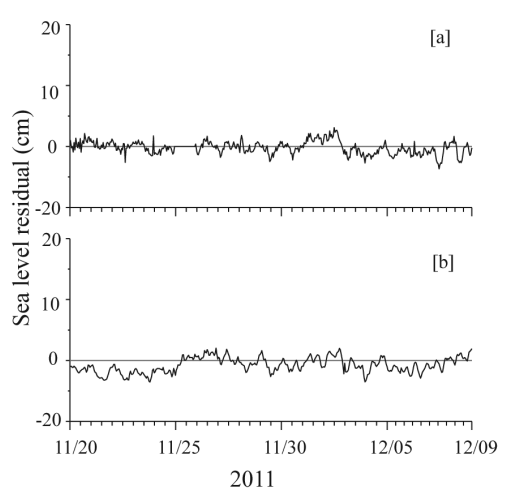

Figure 13. Sea level residual at (a) Minicoy and (b) Hanimaadhoo. Note: 1 - Sea level data at Minicoy (b) Hanimaadhoo is at hourly interval and downloaded from www.gloss-sealevel.org.

a. $\mu<\frac{U_{m} f}{C}$ : coastal peak of increasing in magnitude propagating along the coast with speed $V_{m}$. The maximum peak occurs at the edge $y=V_{m} t$ which is the leading (trailing) edge if $V_{m}>c\left(V_{m}<c\right)$. Where $y$ is alongshore axis and positive towards north, $t$ is time.

b. $\mu>\frac{U_{m} f}{C}$ : coastal peak of constant magnitude moving behind (ahead of) the cyclone if $V_{m}>c\left(V_{m}<c\right)$.

In the present study, our observations indicate that the surge peak lagged E1 up to Verem. At Ratnagiri to Karachi the surge peak leads the E1 with an almost constant amplitude (Table 7). Also note that the surge amplitude is almost constant $(\sim 34 \mathrm{~cm})$ at all the four locations from Karwar to Karachi. The impact of E1 in the BOB at Port Blair (Fig. 3i) and in the northern parts of east coast of India at Kakinada, Gopalpur and Gangavaram (Fig. 3f-h) is not observable. The response of sea level due to E1 at Masirah (Fig. 12k) is also not observable as the location is on the right hand side of the event track. Similarly, the sea level variations at the island locations of Minicoy and Hanimaadhoo are negligible due to E1 (Fig. 13), even though the track of E1 is only $\sim 170$ and $280 \mathrm{~km}$ away, respectively. However, the absence of closed boundary at these Island locations and their locations on the left side of E1 track imply that no surges are predicted. The impact of the E1 is observed only in the AS at the coastal boundary located towards the right side of the event track. 
Table 7. Surge propagation parameters during E1 along the west coast of Indian continent.

\begin{tabular}{lrlrr}
\hline Location & $\begin{array}{r}\text { Peak } \\
(\mathrm{cm})\end{array}$ & $\begin{array}{l}\text { Time of } \\
\text { peak (IST) }\end{array}$ & $\begin{array}{r}\text { Path } \\
\text { between two } \\
\text { locations }(\mathrm{km})\end{array}$ & $\begin{array}{r}\text { Propagation } \\
\text { Speed } \\
\left(\mathrm{m} \mathrm{s}^{-1}\right)\end{array}$ \\
\hline Colombo & 31.6 & 26 Nov 2011 11:30 & & \\
Mandapam & 24.3 & 26 Nov 2011 22:00 & 300 & 7.9 \\
Tuticorin & 21.4 & 27 Nov 2011 15:00 & 110 & 1.8 \\
Kochi (Peak 2) & 12.9 & 27 11 2011 23:30 & 400 & 13.1 \\
Kochi (Peak 1) & 14.14 & 27 Nov 2011 09:30 & & \\
Karwar & 36.9 & 28 Nov 2011 12:00 & 577 & 7.6 \\
Verem & 35.5 & 28 Nov 2011 17:00 & 90 & 5.0 \\
Ratnagiri & 37.0 & 29 Nov 2011 03:00 & 172 & 4.8 \\
Karachi & 31.8 & 1 Dec 2011 07:30 & 1094 & 5.8 \\
Chabahar & 18.4 & 3 Dec 2011 19:30 & 670 & 3.1 \\
Jask & 13.7 & 4 Dec 2011 03:30 & 270 & 6.7 \\
\hline
\end{tabular}

\section{Conclusion}

It is being realised increasingly that a near real-time network of sea level and surface meteorological measurements along the coastal and Island locations of India such as ICON (http://inet.nio.org/) established by CSIR-NIO could play an important role in improving the operational (routine) predictions of coastal flooding and enable to understand the fundamental dynamics of these events. Presently, there are only a few mesoscale weather and sea level networks in some coastal segments of the Indian and eastern Atlantic oceans to observe such events. It is also expected that this kind of relatively inexpensive and simple networks, similar to the one in-house developed and established by CSIR-NIO will be affordable to limited-budget institutions in their natural hazard mitigation efforts.

This study attempts to investigate the meteorologically induced surges and water level oscillations along the select locations in response to the passage of the storm (E1) in the Arabian Sea and "Thane (E2)" in Bay of Bengal. The high frequency water level oscillations observed, such as at Gangavaram during the events are found to be due to the result of harbour resonance. Each location has a typical event spectrum related to the local topography. For example, Rabinovich (1997) observed two prominent peaks in Dimitrova Bay. The first peak with a period of $50 \mathrm{~min}$ related to the amplification of incoming waves over the shelf of the southern Kuril Islands (i.e to the shelf resonance). The second peak with a period of $18.5 \mathrm{~min}$ is caused by the standing oscillation of the bay itself. Some of the locations in the present study showed SLR oscillations around periods of $\sim 92,43$ and 23 (100, 42 and 24) $\mathrm{min}$ in the AS (the BOB). However, influence of local topography is clearly noticeable at shorter time periods at different stations. During E1, even though the local winds are small in magnitude $\left(4-10 \mathrm{~m} \mathrm{~s}^{-1}\right)$, the surges are $39-47 \mathrm{~cm}$ at Ratnagiri, Verem and Karwar with similar peaks in SLR. In this case, the cyclone track is parallel or at an oblique angle to the coastline and hence the surge occurs on longer stretches of the shoreline. Whereas, during E2 (Thane) the cyclone makes a perpendicular approach to the coast at landfall, and therefore the surges are low at Mandapam and Tuticorin, as these stations are on the left side of the Thane track, as compared to the stations on the right side (Gopalpur, Gangavaram and Kakinada). SLR at Gopalpur, Gangavaram and Kakinada remained high for $\sim 9$ days even after the land fall of Thane. The residual sea levels from tide gauge stations along the west coast of India and the coast of Pakistan showed surge peak of constant amplitude propagating northwards with a speed of $\sim 6.5 \mathrm{~m} \mathrm{~s}^{-1}$ during E1. The propagating surges along the western coast have been identified as forced Kelvin waves with almost constant amplitude at Karwar, Verem, Ratnagiri and Karachi. The multi-linear regression using local daily mean winds (cross- and alongshore) in association with the the atmospheric pressure is able to account for up to $69 \%$ of daily mean sea level residual (SLR) at Ratnagiri, Verem and Karwar during E1. However, in the BOB up to $57 \%$ of daily mean SLR is accounted for at Gopalpur, Gangavaram and Kakinada.

\section{The Supplement related to this article is available online at doi:10.5194/os-11-159-2015-supplement.}

Acknowledgements. The authors acknowledge the support and encouragement provided by S. W. A. Naqvi, director, CSIR-NIO, Goa in carrying out this work. They are grateful to Anil Shirgoankar for his consistent technical support in keeping the systems operational. The authors acknowledge the support of the Finolex Industries Limited, Ratnagiri, Maharashtra; Indian Naval Office at Verem, Goa; Estuary View Resort and Survey of India office, Karwar, Karnataka; CSIR-CECRI, Tuticorin, Tamil Nadu; CMFRI, Mandapam, Tamil Nadu; Kakinada Seaports Ltd., Kakinada, Andhra Pradesh; Ganagvaram Ports Limited, Visakhapatnam, Andhra Pradesh and 
Gopalpur Ports Limited, Odisha for providing safe and secured site for sea level and surface meteorological measurements. The authors gratefully acknowledge the financial support (2013-2017) given by the Indian National Centre for the Ocean information Services (INCOIS), Ministry of Earth Sciences, Government of India for maintenance of Autonomous Weather Stations (AWS) under ICON established by CSIR-NIO. Authors thank the two anonymous reviewers for their comments and suggestions. They are also grateful to the editor, John M. Huthnance, for his contributions, which enhanced the quality of the manuscript. This is CSIR-NIO contribution number: 5698 .

Edited by: J. M. Huthnance

\section{References}

Antony, C. and Unnikrishnan, A. S.: Observed characteristics of tide-surge interaction along the east coast of India and the head of Bay of Bengal, Estuar. Coast. Shelf S., 131, 6-11, doi:10.1016/j.ecss.2013.08.004, 2013.

Bell, C., Vassie, J. M., and Woodworth, P. L.: Tidal Analysis Software Kit 2000 (Task 2000), POL/PSMSL Permanent Service for Mean Sea Level, Proudman Oceanographic Laboratory, UK, 2000.

Chittibabu, P., Dube, S. K., Rao, A. D., Sinha, P. C., and Murty, T. S.: Numerical Simulation of extreme sea levels using location specific high resolution model for Gujarat coast of India, Mar. Geod., 23, 133-142, 2000.

Chittibabu, P., Dube, S. K., Rao, A. D., Sinha, P. C., and Murty, T. S.: Numerical simulation of extreme sea levels for the Tamilnadu (India) and Sri Lanka coasts, Mar. Geod., 25, 235-244, doi:10.1080/01490410290051554, 2002.

Das, P. K.: On the Prediction of storm surges, Sadhana, 19, 583595, doi:10.1007/BF02835641, 1994.

Dube, S. K., Rao, A. D., Sinha, P. C., Murty, T. S., and Bahulayan, N.: Storm surge in the Bay of Bengal and Arabian Sea: the problem and its prediction, Mausam, 48, 283-304, 1997.

Dube, S. K., Jain, I., and Rao, A. D.: Numerical storm surge prediction model for the North Indian Ocean and the South China Sea, Disaster Dev., 1, 47-63, 2006.

Dube, S. K., Jain, I., Rao, A. D., and Murty, T. S.: Storm surge modelling for the Bay of Bengal and Arabian Sea, Nat. Hazards, 51, 2-27, doi:10.1007/s11069-009-9397-9, 2009.

Fandry, C. B., Leslie, L. M., and Steedman, R. K.: Kelvin-type coastal surges generated by tropical cyclones, J. Phys. Oceanogr., 14, 582-593, 1984.

Fritz, H. M., Blount, C. D., Albusaidi, F. B., and Al-Harthy, A. H. M.: Cyclone Gonu storm surge in Oman, Estuar. Coastal Shelf S., 86, 102-106, 2010.

Gill, A. E.: Atmosphere-Ocean Dynamics, Academic Press, 662 pp., 1982.

Jain, I., Chittibabu, P., Agnihotri, N., Dube, S. K., Sinha, P. C., and Rao, A. D.: Numerical storm surge model for India and Pakistan, Nat. Hazards, 42, 67-73, doi:10.1007/s11069-006-9060-7, 2007.

Joseph, A.: Tsunamis: Detection, monitoring, and early-warning technologies, Elsevier; New York; USA; 436 pp., 2011.

Joseph, A., Desai, R. G. P., Mehra, P., SanilKumar, V., Radhakrishnan, K. V., VijayKumar, K., AshokKumar, K., Agarvadekar,
Y., Bhat, U. G., Luis, R., Rivankar, P., and Viegas, B.: Response of west Indian coastal regions and Kavaratti lagoon to the November-2009 tropical cyclone Phyan, Nat. Hazards, 57, 293-312, 2011.

Kurian, N. P., Nirupma, N., Baba, M., and Thomas, K. V.: Coastal flooding due to syntopic scale, meso-scale and remote forcing, Nat. Hazards, 48, 259-273, doi:10.1007/s11069-008-92604, 2009.

LeBlond, P. H. and Mysak, L. A.: Waves in the Ocean, Elsevier, 602 pp., 1978.

Mehra, P., Tsimplis, M. N., Prabhudesai, R. G., Joseph, A., Shaw, A. G. P., Somayajulu, Y. K., and Cipollini, P.: Sea level changes induced by local winds on the west coast of India, Ocean Dynam., 60, 819-833, doi:10.1007/s10236-010-0289-z, 2010, 2010.

Mehra, P., Prabhudesai, R. G., Joseph, A., Kumar, V., Agarvadekar, Y., Luis, R., and Viegas, B.: A study of meteorologically and seismically induced water level and water temperature oscillations in an estuary located on the west coast of India (Arabian Sea), Nat. Hazards Earth Syst. Sci., 12, 1607-1620, doi:10.5194/nhess-121607-2012, 2012.

Mehra, P., Desai, R. G. P., Joseph, A., VijayKumar, K., Agarvadekar, Y., Luis, R., and Nadaf, L.: Comparison of sea-level measurements between microwave radar and subsurface pressure gauge deployed at select locations along the coast of India, J. Appl. Remote Sens., 7, 16 pp., doi:10.1117/1.JRS.7.073569, 2013.

Mei, W., Pasquero, C., and Primeau, F.: The effect of translation speed upon the intensity of tropical cyclones over the tropical ocean, Geophys. Res. Lett., 39, L07801, doi:10.1029/2011GL050765, 2012.

Monserrat, S., Vilibic, I., and Rabinovich, A. B.: Meteotsunamis: atmospherically induced destructive ocean waves in the tsunami frequency band, Nat. Hazards Earth Syst. Sci., 6, 1035-1051, doi:10.5194/nhess-6-1035-2006, 2006.

Murty, T. S., Flather, R. A., and Henry, R. F.: The storm surge problem in the Bay of Bengal, Prog. Oceanogr., 16, 195-233, 1986.

Prabhudesai, R. G., Joseph, A., Agarvadekar, A., Dabholkar, D., Mehra, P., Gouveia, A., Tengali, S., Vijaykumar, K., and Parab, A.: Development and implementation of cellular-based real-time reporting and Internet accessible coastal sea level gauge - A vital tool for monitoring storm surge and tsunami, Curr. Sci. India, 90, 1413-1418, 2006.

Prabhudesai, R. G, Joseph, A., Mehra, P., Agarvadekar, Y., Tengali, S., and Vijay kumar: Cellular-based and Internet enabled realtime reporting of the tsunami waves at Goa and Kavaratti Island due to $\mathbf{M}_{w} 8.4$ earthquake in Sumatra on 12th September 2007, Curr. Sci. India, 94, 1151-1157, 2008.

Platzman, G. W.: Ocean tides and related waves, Lectures for the American Mathem-atical Society, 1970, Summer seminars on mathematical problems in the geophysical sciences, Rensselaer Polytechnic Institute, Troy, NY, 94 pp. (also in: Reid, W. H. (Ed.): Mathematical problems in the geophysical sciences, 14, Part 2, 239-291), 1971.

Rabinovich, A. B.: Spectral analysis of tsunami waves: Separation of source and topography effects, J. Geophys. Res., 102, 1266312676, 1997.

Rabinovich, A. B.: Seiches and Harbor Oscillations, Chapter 9, Handbook of Coastal and Ocean Engineering, edited by: Kim, Y. C., World Scientific Publ., Singapore, 2009. 
Rao, A. D., Jain, I., Murthy, M. V. R., Murty, T. S., and Dube, S. K.: Impact of cyclonic wind field on interaction of surge wave computations using Finite- element and Finite-difference models, Nat. Hazards, doi:10.1007/s11069-008-9284-9, 2008.

Rao, A. D., Murty, P. L. N., Jain, I., Kankara, R. S., Dube, S. K., and Murty, T. S.: Simulation of water levels and extent of coastal inundation due to a cyclonic storm along the east coast of India, Nat. Hazards, 66, 1431-1441, doi:10.1007/s11069-012-0193-6, 2013.

SLOSH: Sea, Lake, and Overland Surge from Hurricanes, a computerized model developed by the National Weather Service (NWS), US, to estimate storm surge heights and winds resulting from historical, hypothetical, or predicted hurricanes, SLOSH Display Training, 2003.
Sundar, D., Shankar, D., and Shetye, S. R.: Sea level during storm surges as seen in tide-gauge records along the east coast of India, Curr. Sci. India, 77, 1325-1332, 1999.

Thompson, R. E.: On the generation of Kelvin-type waves by atmospheric disturbances, J. Fluid Mech., 42, 657-670, 1970.

Wang, Z., DiMarco, S. F., Stossel, M. M., Zhang, X., Howard, M. K., and du Vall, K.: Oscillation responses to tropical Cyclone Gonu in northern Arabian Sea from a moored observing system, Deep-Sea Res., 64, 129-145, doi:10.1016/j.dsr.2012.02.005, 2012. 